Jurnal Manajemen Kesehatan Yayasan RS. Dr. Soetomo Vol.4 No.2 Oktober 2018

Print ISSN 2477-0140 Online ISSN 2581-219X

www.jurnal.stikes-yrsds.ac.id

\title{
Faktor-faktor yang Mempengaruhi Timbulnya Carpal Tunnel Syndrome pada Pengendara Ojek
}

\section{Factors Influencing Carpal Tunnel Syndrome Among 'Ojek’ Driver}

\author{
Fanny S. Farhan*, Aisyah A. Kamrasyid* \\ *Fakultas Kedokteran dan Kesehatan Universitas Muhammadiyah Jakarta \\ Email : fannybudiyan@gmail.com
}

\begin{abstract}
ABSTRAK
Carpal Tunnel Syndrome (CTS) adalah masalah kesehatan yang diakibatkan oleh penekanan atau terjepitnya saraf medianus yang melewati terowongan karpal pada ekstremitas atas. Penelitian ini bertujuan untuk mengetahui faktor-faktor yang mempengaruhi timbulnya keluhan tersebut pada pengendara ojek di Kecamatan Kramat Jati Jakarta Timur. Penelitian ini adalah penelitian observasional analitik dengan desain cross sectional. Responden adalah seluruh tukang ojek yang ditemuin selama kurun waktu penelitian di Kecamatan Kramat Jati berjumlah 96 orang. Instrument penelitian berupa kuesioner dan pemeriksaan tinnel test pada araf medianus. Berdasarkan analisis chi square, terdapat hubungan bermakna antara postur pergelangan tangan dengan keluhan CTS $(\mathrm{p}<0.05)$, faktor usia dengan keluhan CTS $(\mathrm{p}<0.05)$ dan indeks massa tubuh dengan keluhan CTS $(\mathrm{p}<0.05)$. Berdasarkan hasil penelitian, dapat diketahui tukang ojek yang mengalami keluhan Carpal Tunnel Syndrome sebanyak 72 responden (75\%). Faktor yang dominan menyebabkan timbulnya keluhan CTS adalah postur pergelangan tangan, faktor usia dan indeks massa tubuh.
\end{abstract}

Kata Kunci : Pergelangan Tangan, Ojek, Keluhan Carpal Tunnel Syndrome (CTS)

\begin{abstract}
Motorcycle driver known as Ojek driver, is one of the jobs at risk of Carpal Tunnel Syndrome (CTS), a medical condition due to compression of the median nerve with main symptoms are pain and numbness. The aim of this research is to investigate factors influencing CTS among ojek drivers. An observational study with cross sectional methodes was apply to identify factors related with CTS symptoms among ojek driver in east Jakarta region. Data were ocollected from questionner and CTS physical examination. Total sample of 96 male ojek driver participants were collected. Chi square analysis showed statistically significant between wrist posture, age and body masss index $(p<0.05)$ to the occurance of CTS. wrist posture, age and body masss index are most common factors that influence the symptom of carpal tunnel among ojek driver in Jakarta.
\end{abstract}

Keywords : Posture, Ojek, Carpal Tunnel Syndrome 
Fanny S. Farhan, Aisyah A. Kamrasyid : Faktor-faktor yang Mempengaruhi ...

\section{PENDAHULUAN}

Carpal Tunnel Syndrome (CTS) adalah penyakit yang disebabkan terjepitnya saraf medianus pada ekstremitas atas tepatnya pergelangan tangan yang melalui terowongan karpal (Ginsberg, 2008). Penyakit ini merupakan salah satu yang sering dijumpai di kalangan buruh industri. Menurut data National Health Interview Study (NIHS) diperkirakan angka prevalensi sindrom metakarpal pada subjek dewasa adalah sebesar 1,55\% (2,6 juta jiwa).

Carpal Tunnel Syndrome (CTS) adalah salah satu jenis Cumulative Trauma Disorders (CTD). Cumulative Trauma Disorders dapat disebabkan oleh gerakan repetitif dalam kurun waktu yang lama. Di Amerika Serikat (USA), trauma kumulatif (Cumulative trauma disorders) adalah penyebab terjadinya lebih dari 50\% penyakit akibat kerja dengan insidens 21 kasus per 100.000 pekerja per tahun (Setiawan, 2009). CTS adalah salah satu dari 3 jenis penyakit terbanyak di dalam kelompok CTD pada lengan atas, angka kejadian sindrom terowongan karpal adalah 40\%, tendosinovitis sebanyak 32\% dan De Quervan's syndrome 12\%, sedangkan infeksi pada epicondilus sebanyak 20\% (Tana, 2003).

Di Indonesia, prevalensi penyakit ini dalam masalah kerja belum diketahui karena minimnya laporan kejadian. Penelitian pada pekerjaan dengan risiko tinggi di pergelangan tangan dan tangan mendapatkan sindrom terowongan karpal antara $5,6 \%-14,8 \%$ (Tana, 2003).

Dua mekanisme menyebabkan tekanan kumulatif berulang dan cedera pergelangan ketika mengendarai sepeda motor. Pertama, setang menerima sejumlah besar getaran dari mesin dan permukaan jalan yang tidak teratur. Kedua, perangkat pada setang dikendalikan oleh pengendara bermotor. Tangan kanan pengemudi mengontrol throttle (untuk menambah atau mengurangi aliran gas) dan rem depan, dan tangan kiri mengontrol kopling. Ini dapat menambah tekanan berulang yang dihasilkan pada pergelangan tangan (Manes, 2012).

Penyakit akibat kerja disebabkan akibat hubungan kerja atau yang disebabkan oleh pekerjaan maupun sikap dalam bekerja. Faktor fisik dan kondisi lingkungan kerja, bisa menjadi faktor resiko cidera atau patologis pada syaraf. Faktor fisik tersebut diantaranya gerakan dengan kekuatan dan berulang, tekanan 
kontinyu pada otot dan tekanan oleh alat mesin maupun getarannya, bisa juga akibat paparan suhu serta postur kerja yang kurang nyaman, banyak dari faktor tersebut akan semakin mempengaruhi seiring berjalannya masa kerja seseorang. Lama waktu kerja, kurangnya waktu istirahat serta pekerjaan yang monoton dapat meningkatkan resiko terjadinya Carpal Tunnel Syndrome (CTS).

Penelitian yang dilakukan oleh Armstrong (2008) di kawasan industri kerja, terdapat beberapa faktor kontrol dari perkembangan CTS yaitu gender, umur, masa tubuh dan penyakit sistemik yang diderita. CTS adalah manifestasi dari kondisi kesehatan general dan aktivitas fisik yang repetitif sehingga mengakibatkan peningkatan tekanan pada saraf medianus saat melewati terowongan karpal (Bachrodin, 2012). Pada pengendara ojek, postur pergelangan tangan pengendara bermotor berperan dalam menyebabkan CTS, sehingga kelompok ini merupakan kelompok yang berisiko menderita CTS. Tingkat prevalensi lebih tinggi pada CTS telah ditemukan pada kelompok tertentu dengan gerakan berulang tangan, terutama fleksi pergelangan tangan dan ekstensi lengan. Faktor-faktor ini tentu mewakili pekerjaan sebagai tukang ojek (Mithun Pai, 2014). Pengendara ojek merupakan salah satu pekerjaan yang beresiko untuk mengalami CTS sehingga penelitian ini berujuan untuk meneliti faktor-faktor yang berperan terhadap timbulnya keluhan CTS pada pengendara ojek.

\section{METODE}

Penelitian ini dilakukan di Kecamatan Kramat Jati Jakarta Timur tahun 2015, dan merupakan penelitian jenis analitik observasional dengan metode cross sectional. Variabel independen riset ini adalah postur pergelangan tangan sedangkan variabel dependen dalam penelitian ini adalah keluhan Carpal Tunnel Syndrome.data karakteristik dari tukang ojek didapatkan dengan penggunaan kuesioner. Penelitian ini yang menjadi populasi adalah para tukang ojek yang beroperasi di Kecamatan Kramat Jati Jakarta Timur pada tahun 2015. Total sampel adalah seluruh tukang ojek yang ditemui selama rentang waktu penelitian sebanyak 96 orang. Kuesioner dalam penelitian ini ditanyakan pada responden yang berisi pertanyaan mengenai nama, umur, indeks massa tubuh, riwayat 
Fanny S. Farhan, Aisyah A. Kamrasyid : Faktor-faktor yang Mempengaruhi ...

penyakit, lama kerja, masa kerja, pemakaian alat pelindung diri, postur pergelangan tangan dan gejala Carpal Tunnel Syndrome (CTS). Data yang didapat kemudian dianalisis dengan metode Chi square.

\section{HASIL}

Tabel 1. Karakteristik responden

\begin{tabular}{llrr}
\hline \multicolumn{1}{c}{ Karakteristik } & $\begin{array}{c}\text { Jumlah } \\
\text { (n) }\end{array}$ & $\begin{array}{c}\text { Presentase } \\
\text { (\%) }\end{array}$ \\
\hline Usia & $<40$ tahun & 32 & 33,3 \\
Masa kerja & $\geq 40$ tahun & 64 & 66,7 \\
& $<4$ tahun & 10 & 10,4 \\
Lama Kerja & $\geq 4$ tahun & 86 & 89,6 \\
& $\leq 8$ jam & 29 & 30,2 \\
Indeks massa tubuh & $>8$ jam & 67 & 69,8 \\
& Berat badan kurang & 6 & 6,3 \\
Alat pelindung diri & Normal & 55 & 57,3 \\
& Obesitas & 35 & 36,5 \\
Postur pergelangan & Ya & 23 & 24,0 \\
& Tidak & 73 & 76,0 \\
Keluhan CTS & Janggal & 34 & 35,4 \\
& Tidak & 62 & 64,6 \\
& Tidak & 24 & 25,0 \\
& Ya & 72 & 75,0 \\
\hline
\end{tabular}

Berdasarkan tabel 1 diperoleh karakteristik usia responden terbanyak pada kelompok $\geq 40$ tahun sebanyak 64 responden (66,7\%), responden memiliki masa kerja $\geq 4$ tahun yaitu sebanyak 86 responden (89,6\%). Sedangkan responden yang memiliki masa kerja < 4 tahun sebanyak 10 responden (10,4\%). Berdasarkan pada penelitian sebelumnya dapat dikategorikan bahwa masa kerja lebih dari 4 tahun berisiko mengalami keluhan CTS. Pada penelitian ini, sebagian besar responden memiliki jam kerja > 8 jam yaitu sebanyak 67 responden (69,8\%).

Untuk jam kerja dalam sehari tersingkat adalah 3 jam, sedangkan untuk terlama adalah 24 jam. Pada penelitian ini jam kerja dikategorikan berdasarkan Undang-Undang No.13 Tahun 2003 Pasal 77 ayat 1 yaitu 6-8 jam. Di Indonesia, dianjurkan bahwa lamanya waktu kerja sehari maksimum 8 jam kerja. Sebagian besar responden memiliki indeks masa tubuh yang normal yaitu sebanyak 55 responden (57,3\%). Responden dengan kategori indeks masa tubuh obesitas 
sebanyak 35 responden (36,5\%). Responden tidak memiliki riwayat penyakit yaitu sebanyak 59 responden (61,5\%). Sedangkan responden yang lain yang memiliki riwayat penyakit adalah sebanyak 37 responden (38,5\%). Sebagian besar responden tidak menggunakan alat pelindung diri (sarung tangan) yaitu sebanyak 73 responden (76,0\%).

Responden yang menggunakan alat pelindung diri (sarung tangan) adalah sebanyak 23 responden (24,0\%). Diketahui responden yang menggunakan handle bar pada sepeda motor dengan posisi janggal pada pergelangan tangan adalah sebanyak 34 responden (35,5\%) dan responden yang menggunakan handle bar dengan posisi normal pada pergelangan tangan sejumlah 62 responden $(64,6 \%)$. Responden mengalami keluhan CTS yaitu sebanyak 72 responden (75,0\%). Responden yang tidak mengalami keluhan CTS sejumlah 24 responden (25,0\%). Keluhan berupa nyeri, kesemutan, kaku dan mati rasa.

Tabel 2 Gejala CTS Lengan Kiri

\begin{tabular}{lrr}
\hline Keluhan CTS Lengan Kiri & Jumlah (n) & $\begin{array}{r}\text { Presentase } \\
(\%)\end{array}$ \\
\hline Sakit/nyeri & 12 & 12,5 \\
Kesemutan & 39 & 40,6 \\
Kaku & 19 & 19,8 \\
Mati Rasa & 12 & 12,5 \\
\hline
\end{tabular}

Berdasarkan Tabel 2 di peroleh informasi kebanyakan responden mengalami keluhan kesemutan di CTS Lengan kiri sebesar 40,6\%. Kemudian di lanjutkan dengan rasa kaku $19,8 \%$.

Tabel 3 Gejala CTS Lengan Kanan

\begin{tabular}{lrr}
\hline Keluhan CTS Lengan Kanan & Jumlah (n) & $\begin{array}{r}\text { Presentase } \\
(\%)\end{array}$ \\
\hline Sakit/nyeri & 28 & 29,2 \\
Kesemutan & 55 & 57,3 \\
Kaku & 28 & 29,2 \\
Mati Rasa & 17 & 12,7 \\
\hline
\end{tabular}

Berdasarkan Tabel 3 di peroleh informasi kebanyakan responden mengalami keluhan kesemutan di CTS Lengan kiri sebesar 57,3\%. Kemudian di lanjutkan dengan rasa kaku dan nyeri sebesar $29,2 \%$. 
Fanny S. Farhan, Aisyah A. Kamrasyid : Faktor-faktor yang Mempengaruhi ...

Tabel 4 Analisis Bivariat

\begin{tabular}{|c|c|c|c|c|c|c|c|}
\hline \multirow[t]{3}{*}{ Karakteristik } & \multicolumn{4}{|c|}{ Keluhan CTS } & \multirow{3}{*}{ OR } & \multirow{3}{*}{$\begin{array}{c}\text { CI } \\
(95 \%)\end{array}$} & \multirow[t]{3}{*}{$\mathrm{P}$} \\
\hline & \multicolumn{2}{|c|}{ Tidak } & \multicolumn{2}{|r|}{ Ya } & & & \\
\hline & $\mathrm{n}$ & $\%$ & $\mathrm{n}$ & $\%$ & & & \\
\hline \multicolumn{8}{|l|}{ Postur Janggal } \\
\hline Tidak & 23 & $37,1 \%$ & 39 & $62,9 \%$ & 19,46 & & 0,0 \\
\hline Ya & 1 & $2,9 \%$ & 33 & $97,1 \%$ & & $2,49-151,9$ & \\
\hline \multicolumn{8}{|l|}{ Umur } \\
\hline$<40$ tahun & 12 & $37,5 \%$ & 20 & $62,5 \%$ & 2,60 & $1,004-6,7$ & 0.046 \\
\hline$\geq 40$ tahun & 12 & $18,8 \%$ & 52 & $81,2 \%$ & & & \\
\hline $\begin{array}{l}\text { Indeks Massa Tubuh } \\
\text { Normal }\end{array}$ & 11 & $20,4 \%$ & 43 & 79,6 & _- & & 0013 \\
\hline Underweight & 5 & $71,4 \%$ & 2 & $28,6 \%$ & & & \\
\hline Obesitas & 8 & $22,9 \%$ & 27 & $77,1 \%$ & & & \\
\hline
\end{tabular}

Hasil uji chi square memperlihatkan hubungan bermakna antara posisi janggal pergelangan tangan terhadap keluhan CTS (p0.0), hubungan usia dengan keluhan CTS pada tukang ojek dengan OR 2,60 menunjukkan bahwa usia $>40$ tahun 2,6x lebih berisiko mengalami keluhan CTS jika dibandingkan dengan usia $<40$ tahun. Uji chi square juga didapatkan hubungan massa tubuh dengan keluhan CTS p 0,013. Hasil ini menunjukkan indeks masa tubuh berperan signifikan terhadap munculnya keluhan CTS pada tukang ojek.

\section{PEMBAHASAN}

Carpal Tunnel Syndrome (CTS) disebabkan oleh lesi apapun yang secara signifikan mengurangi ukuran canalis carpi, atau yang lebih sering menambah ukuran beberapa dari sembilan struktur (atau lapisannya) yang berjalan melaluinya (misalnya, peradangan pada vagina synovialis). Retensi cairan, infeksi, dan latihan tangan berlebih dapat menyebabkan pembengkakan tendo atau vagina synovialisnya (Moore, 2013). Penyebab CTS menjadi 3 faktor, yaitu: faktor intrinsik, faktor penggunaan tangan (penggunaan tangan yang berhubungan dengan hobi dan penggunaan tangan yang berhubungan dengan pekerjaan), dan faktor trauma (Salawati, 2014).

CTS yang terjadi berhubungan dengan penggunaan tangan karena hobi atau pekerjaan adalah sebagai akibat inflamasi/pembengkakan tenosinovial di 
dalam terowongan karpal. Penggunaan tangan yang berhubungan dengan hobi, contohnya adalah pekerjaan rumah tangga (menjahit, merajut, menusuk, memasak), kesenian, dan olahraga. CTS yang berhubungan dengan pekerjaan meliputi kegiatan yang membutuhkan kekuatan, penggunaan berulang atau lama pada tangan dan pergelangan tangan, terutama jika faktor risiko potensial tersebut muncul secara bersamaan misalnya penggunaan tangan yang kuat terutama jika ada pengulangan, penggunaan tangan dikombinasikan dengan beberapa unsur kekuatan terutama untuk waktu yang lama, konstan dalam mengcegkeram benda, memindahkan atau menggunakan tangan dan pergelangan tangan terhadap perlawanan atau dengan kekuatan, menggunakan tangan dan pergelangan tangan untuk geteran teratur yang kuat, tekanan biasa atau intermitten pada pergelangan tangan (Salawati, 2014). Gerakan tangan, mengetuk, fleksi, dan ekstensi yang berulang-ulang, serta mengetik menyebabkan kompresi saraf median diterowongan karpal merupakan hasil dari ketidaksesuaian antara volume isi kanal dan ukuran relatif (Saerang, 2015).

Gambaran klinis CTS adalah perasaan sakit atau kebas di tangan atau lengan terutama pada malam hari atau saat bekerja, atrofi otot eminesia tenar, hilangnya sensasi pada sepanjang distribusi saraf medians. Keluhan awal yang dirasakan biasanya hanya berupa gangguan sensorik saja. Namun pada tahap selanjutnya dapat dijumpai pengecilan otot-otot thenar dan otot-otot lainnya yang dipersarafi oleh nervus medianus (Rambe, 2004). Pada penelitian ini, usia, postur pergelangan tangan dan indeks massa tubuh berpengaruh terhadap timbulnya keluhan CTS.

Usia merupakan satu faktor pencetus munculnya beberapa keluhan penyakit. Kategori usia pada penelitian ini dibagi menjadi dua yaitu tukang ojek yang berusia $<40$ dan $\geq 40$ karena Carpal Tunnel Syndrome (CTS) sering ditemukan pada populasi dewasa, yaitu paling sering ditemukan pada usia 40 - 60 tahun (Bachrodin, 2011). Berdasarkan hasil penelitian didapatkan bahwa terdapat hubungan antara usia dengan keluhan CTS.

Penelitian ini sejalan dengan penelitian yang dilakukan oleh Rusdi (2010) yang menyimpulkan bahwa rerata umur buruh pekerja perkayuan Brumbung 
Fanny S. Farhan, Aisyah A. Kamrasyid : Faktor-faktor yang Mempengaruhi ...

sebagian besar memiliki umur di atas 40 tahun, dimana pertambahan umur dapat memperbesar resiko terjadinya sindroma CTS karena penyakit ini dapat menyerang orang dengan usia antara 29-60 tahun.

Penelitian lain yang juga sejalan adalah penelitian yang dilakukan Kurniawan (2005) yang menunjukkan bahwa terdapat pengaruh usia terhadap Carpal Tunnel Syndrome. Pada penelitian tersebut didapatakan $\mathrm{P}$ value = 0,001dan usia 40 tahun keatas berisiko terkena Carpal Tunnel Syndrome 6x lebih besar dibandingkan dengan usia dibawah 40 tahun (Tarwaka, 2004).

Hal ini juga sejalan dengan penelitian Suherman (2012) yang menyatakan bahwa ada hubungan antara usia dengan Carpal Tunnel Syndrome (CTS) pada petugas rental komputer dengan P value $=0,001$, dimana prevalensi CTS lebih tinggi pada kelompok usia 24-34 tahun dibandingkan dengan usia $<24$ tahun (Suherman, 2012).

Indeks Masa Tubuh (IMT) merupakan metode yang mudah untuk memantau status gizi individu. Peneliti membuat klasifikasi menjadi 3 kategori yaitu $\leq 18,5 \mathrm{~kg} / \mathrm{m}^{2}$ untuk kategori underweight, 18,5-25,0 kg/m² untuk kategori normal, dan $>25 \mathrm{~kg} / \mathrm{m}^{2}$ untuk kategori obesitas. Berdasarkan hasil analisa bivariat diketahui IMT berhubungan dengan keluhan CTS. Status gizi yang berlebih dapat menyebabkan penumpukan cairan atau menyebabkan bertambahnya isi carpal tunnel sehingga dapat memperbesar risiko terjadinya CTS. Hal tersebut sesuai dengan penelitian (Iriani, 2010) yang menunjukkan hubungan yang signifikan antara obesitas dan keluhan CTS dengan p value $=0,015$.

Salah satu faktor yang dapat menyebabkan Carpal Tunnel Syndrome (CTS) adalah trauma akibat gerakan fleksi-ekstensi berulang pergelangan tangan dengan kekuatan yang cukup seperti pada pekerjaan tertentu yang banyak memerlukan gerakan pergelangan tangan. Hal tersebut yang dilakukan oleh tukang ojek saat mengendarai sepeda motor. Untuk pengukuran variabel ini menggunakan kuesioner yang memperlihatkan postur pergelangan tangan ekstensi yang ekstrim (Harahap, 2003).

Berdasarkan tabel 1 diketahui responden yang menggunakan handle bar pada sepeda motor dengan posisi janggal pada pergelangan tangan adalah 
sebanyak 34 responden (35,5\%) dan responden yang menggunakan handle bar dengan posisi tidak janggal pada pergelangan tangan sebanyak 62 responden (64,6\%). Hasil uji chi square menunjukkan bahwa ada hubungan yang bermakna antara postur pergelangan tangan dengan keluhan CTS. Tukang ojek dalam mengenderai sepeda motor banyak melakukan gerakan tangan yang sifatnya repetitif dengan postur pergelangan tangan fleksi maupun ekstensi. Hal inilah yang dapat memicu penyebab terjadinya penelakan pada saraf dan akhirnya menimbulkan CTS. Penelitian ini yang sejenis dilakukan Suherman (2012) pada petugas penyewaan dan penetikan komputer. Penelitian tersebut menyimpulkan terdapat signifikansi dengan $\mathrm{p}$ value $=0,00$ yang menunjukkna hubungan yang signifikan antara posisi tangan dengan kejadian CTS (Suherman, 2012).

Pada penelitian yang dilakukan oleh Kurniawan dkk (2008) pada pekerja pemetik melati, menunjukkan $\mathrm{p}$ value $=0,013$ yang artinya ada hubungan signifikan antara posisi tangan dengan kejadian CTS (Kurniawan, 2008). Penelitian ini dapat memberikan informasi dan saran kepada para pengendara ojek untuk mengurangi keluhan CTS yang diderita diantaranya, melakukan latihan pada tangan dan pergelangan tangan yang sederhana selama 4-5 menit setiap jam.

Latihan ini dapat membantu mengurangi risiko berkembangnya atau mencegah CTS. Latihan berguna bagi pekerja yang bekerja dengan gerakan berulang. Peregangan dan latihan dapat memperkuat otot pergelangan tangan dan tangan, sehingga memperbaiki aliran darah pada daerah tersebut. Latihan harus dimulai dengan periode pemanasan yang pendek disertai periode istirahat dan bila mungkin menghindari peregangan berlebihan pada otot tangan dan jari-jari. Disarankan pula bagi tukang ojek agar menjaga pola makan dan nurisi tercukupi, sehingga akan mengurangi kemungkinan terjadinya keluhan CTS.

Penggunaan alat pelindung diri berupa sarung tangan khusus yang terbuat dari karet elastis juga akan lebih baik, agar dapat menyangga dan membatasi pergerakan pergelangan tangan dan menghindari terjadinya penekanan secara langsung terhadap nervus medianus. 
Fanny S. Farhan, Aisyah A. Kamrasyid : Faktor-faktor yang Mempengaruhi ...

\section{SIMPULAN}

Secara umum hampir sebagian besar tukang ojek di Kecamatan Kramat Jati Jakarta Timur mengalami keluhan CTS. Statistik menunjukkan bahwa ada pengaruh usia, indeks massa tubuh dan postur pergelangan tangan terhadap keluhan CTS pada tukang ojek di Kecamatan Kramat Jati Jakarta Timur. Sebagai upaya menghindari terjadinya keluhan CTS disarankan agar tukang ojek melakukan gerakan pemanasan pada pergelangan tangan selama sekitar lima menit agar dapat mengurangi risiko munculnya keluhan CTS.

\section{UCAPAN TERIMA KASIH}

Ucapan Terima kasih kami sampaikan kepada Fakultas Kedokteran dan Kesehatan Universitas Muhammadiyah Jakarta atas bimbingan dan dukungan kepada peneliti.

\section{DAFTAR PUSTAKA}

Bachrodin, Moch. 2011. Carpal Tunnel Syndrome. Malang: Fakultas Kedokteran Universitas Muhammadiyah Malang: hal.7(14).

Ginsberg, Lionel. 2008. Lecture Notes Neurologi Edisi Kedelapan. Jakarta: Erlangga.

Harahap, Rudiansyah. 2003. Praktis Carpal Tunnel Syndrome. Cermin Dunia Kedokteran.

Iriani, Tirsa. 2010. Hubungan Repetitive Motion dengan Keluhan Carpal Tunnel syndrome Pada Pekerjaan Menjahit di Bagian Konveks I PT. Dan Liris Suhoharjo. Skripsi. Surakarta: Program Studi Fakultas Kedokteran. Universitas Sebelas Maret Surakarta.

Kurniawan, Bina. 2008. Faktor Risiko Kejadian Carpal Tunnel Syndrome (CTS) Pada Wanita Pemetik Melati di Desa Karangcengi, Purbalingga. Jurnal Promosi Kesehatan Indonesia;3(1).

Lusianawaty Tana. 2003. Sindrom Terowongan Karpal pada Pekerja: Pencegahan dan Pengobatannya. Jurnal Kedokteran Trisakti.; Vol. 22 (3)

Manes, Harvey R, MD, 2012. Prevalence of Carpal Tunnel Syndrome. Scholarly Journals, United States.

Mithun Pai BH., et al. 2014. Symptoms of Carpal Tunnel Sydrome in a dental work force of a developing country: Internatinal Journal of Advanced Research.

Moore, Keith L. 2013. Anatomi Berorientasi Klinis Edisi Kelima Jilid 2. Jakarta: Erlangga.

Rusdi, Yusuf. 2015. Hubungan antara Geteran Mesin Produksi dengan Carpal Tunnel Syndrome. Jurnal Kesehatan Masyarakat. (2), 89-94.

Saerang, Denniel et al. 2015. Insiden Carpal Tunnel Syndrome Berdasarkan Anamnesis Pada Karyawan Bank di Kota Bitung Sulawesi Utara.

Salawati Liza. 2014. Carpal Tunnel Syndrome. Jurnal Kedokteran Syiah Kuala Volume 14 Nomer 1. 
Setiawan, Budi, 2009. Buku Ajar Ilmu Penyakit Dalam. Jakarta: Interna Publishing.

Suherman, Bambang.2012. Beberapa Faktor yang berhubungan dengan Kejadian CTS pada petugas Rental Komputer di Kelurahan Kahuripan Kota Tasikmalaya. Tasikmalaya ; Universitas Siliwangi.

Tarwaka, dkk. 2004. Ergonomi untuk Keselamatan, Kesehatan Kerja dan Produktivitas. Surakarta. 